\title{
Long-segment, supercharged, pedicled jejunal flap for total esophageal reconstruction
}

\author{
Anthony J. Ascioti, MD, ${ }^{a}$ Wayne L. Hofstetter, MD, ${ }^{a}$ Michael J. Miller, MD, ${ }^{b}$ David C. Rice, MD, ${ }^{a}$
}

Stephen G. Swisher, MD, ${ }^{a}$ Ara A. Vaporciyan, MD, ${ }^{a}$ Jack A. Roth, MD, ${ }^{a}$ J. B. Putnam, MD, ${ }^{d}$ W. Roy Smythe, MD,

Barry W. Feig, MD, ${ }^{c}$ Paul F. Mansfield, MD, ${ }^{c}$ Peter W. T. Pisters, MD, ${ }^{c}$ Marla T. Torres, BS, ${ }^{a}$ and Garrett L. Walsh, MD ${ }^{a}$

From the Departments of Thoracic and Car-
diovascular Surgery, ${ }^{\mathrm{a}}$ Plastic Surgery, ${ }^{\mathrm{b}}$ and
Surgical Oncology, ${ }^{\mathrm{c}}$ The University of Texas
M.D. Anderson Cancer Center, Houston,
Tex; the Department of Thoracic Surgery,
Vanderbilt University Medical Center,
Nashville, Tenn; and the Department
of Surgery, The Scott and White Clinic, ${ }^{\text {e }}$
Temple, Tex.

Read at the Eighty-fifth Annual Meeting of The American Association for Thoracic Surgery, San Francisco, Calif, April 10-13, 2005.

Received for publication April 8, 2005; revisions received June 20, 2005; accepted for publication June 30, 2005.

Address for reprints: Wayne L. Hofstetter, MD, Division of Thoracic and Cardiovascular Surgery, The University of Texas M.D. Anderson Cancer Center, Unit 445, 1515 Holcombe Blvd, Houston, TX 77030 (E-mail: whofstetter@mdanderson.org).

J Thorac Cardiovasc Surg 2005;130:1391-8 $0022-5223 / \$ 30.00$

Copyright () 2005 by The American Association for Thoracic Surgery

doi:10.1016/j.jtcvs.2005.06.032
Objective: Many patients with cancer have limited esophageal reconstruction options when the stomach is unavailable as a replacement conduit or when longsegment discontinuity exists. Jejunum has been used as an alternative conduit, both as a pedicled or free flap interposition; however, reports of this are usually limited to short-segment repairs. Microvascular augmentation of a pedicled jejunal flap allows creation of a longer conduit, making it possible to replace the entire esophagus with jejunum. Few reports describe this technique in patients with cancer. We report our initial experience with "supercharged" pedicled jejunum as an alternative conduit for total esophageal reconstruction.

Methods: Review of a prospectively collected departmental database was performed to identify those patients who underwent total esophageal reconstruction with supercharged pedicled jejunum. Data regarding their perioperative course and postoperative function were gathered from the prospectively collected clinical data, review of hospital records, and patient interviews.

Results: Total esophageal reconstruction with supercharged pedicled jejunum was attempted in 26 patients (age range, 37-74 years) between March 2000 and April 2004. Twenty-four of 26 patients were ultimately discharged with an intact supercharged pedicled jejunum flap, for an overall success rate of $92.3 \%$. One patient experienced intraoperative flap loss caused by technical difficulties harvesting the flap and never had the flap interposed. One other flap loss occurred in the early postoperative period in a patient who had multisystem organ failure after a prolonged reconstruction. Cervical anastomotic leaks occurred in $19.2 \%(5 / 26)$ of the patients. Two midconduit leaks occurred that were suspicious for iatrogenic perforation from nasogastric tube placement; one required reoperation. One additional early reoperation was performed for cecal ischemia. There were no mortalities. Functional results were available in $95.4 \%$ (21/22) of the patients receiving supercharged pedicled jejunum who survived at least 6 months after reconstruction. At the time of follow-up, 95\% (20/21) of the patients were tolerating regular diet, and $76.2 \%(16 / 21)$ did not require any supplemental alimentation. Ninety-five percent (20/21) of the patients were free from reflux symptoms, and $80.9 \%(17 / 21)$ had no dumping symptoms. Only 1 patient required dilation of a midconduit stricture. One patient required late reoperation for conduit redundancy.

Conclusions: Supercharged pedicled jejunum is a suitable alternative conduit for total esophageal replacement in patients with cancer with otherwise limited reconstructive options. Functional outcomes are excellent, despite the severity of disease and technical challenges in this patient population.

$\mathrm{E}$ sophageal reconstruction remains a challenge, even in the most experienced hands. Although the stomach is widely considered the reconstructive conduit of choice, especially after cancer operations, its use as an esophageal replacement has inherent limitations that can potentially affect a patient's functional 


\section{Abbreviations and Acronyms}

SPJ $=$ supercharged pedicled jejunum

outcome and quality of life. In certain instances the stomach is simply not available as a replacement conduit because of disease involvement or prior gastric surgery.

The use of a pedicled colon interposition to replace the esophagus is well described in the literature, and this conduit might avoid some of the long-term side effects of gastric pull-up procedures. However, this technique also has several distinct disadvantages, including an increased need for remedial procedures when compared with gastric conduits. ${ }^{1-5}$ Similarly, the colon might be unavailable because of a previous operation or intrinsic diseases, such as diverticulosis, polyps, or cancer.

The jejunum might represent the final alternative for esophageal reconstruction in some patients and offers several potential advantages when compared with the stomach and colon. Jejunum is readily available, is generally free of intrinsic disease, closely approximates the diameter of the esophagus, and might maintain intrinsic aboral peristalsis after transfer. Despite these attributes, the use of jejunum has mainly been limited to partial esophageal reconstructions with pedicled interpositions because of the limitations of the mesenteric blood supply.

Advances in microsurgical technique have now expanded the role of the jejunum in esophageal reconstruction, allowing for the creation of longer conduits through "supercharging." This involves microvascular augmentation of the proximal mesenteric circulation of a jejunal flap through an anastomosis with the internal thoracic or cervical vessels, making it possible to replace the entire esophagus with jejunum. This report represents our initial experience with supercharged pedicled jejunum (SPJ) as an alternative conduit for total esophageal reconstruction.

\section{Patients and Methods}

After approval by our institutional review board, we conducted an analysis of 293 patients who underwent esophagectomy at our institution between March 2000 and April 2004. Retrospective review of our departmental database (consisting of prospectively defined data elements collected concurrently with clinical care of the individual patient) allowed identification of those patients who underwent total esophageal reconstruction with an SPJ flap during that time period. Data regarding their preoperative characteristics and perioperative course were gathered through analysis of the aforementioned database and subsequent review of hospital records. Information on jejunal conduit function was collected on patients who survived at least 6 months after their reconstruction. The 6-month time period provided patients with an opportunity to recover from their operations and adjust to their new anatomy. Jejunal function was assessed through review of hospital records, as well as telephone interviews with the surviving patients. Specific issues addressed during these interviews included alterations in eating habits, weight status, need for supplemental alimentation, degree of dysphagia, reflux, dumping, and overall satisfaction with the results of the operation. Patients were also questioned about the need for conduit dilation or remedial procedures.

\section{Operative Technique}

All patients underwent esophageal reconstruction with a 1-stage procedure involving both the thoracic and microvascular plastic surgical teams. Patients in whom the esophagus was intact underwent either a transhiatal or 3-field esophagectomy with a cervical anastomosis.

At the time of laparotomy, the stomach was mobilized and divided at the appropriate margin with a linear cutting stapler. A gastric drainage procedure (either pyloroplasty or pyloromyotomy) was routinely performed. The conduit was harvested from the proximal jejunum beginning approximately $40 \mathrm{~cm}$ distal to the ligament of Treitz. The mesentery of the jejunum was examined with a fiberoptic light to transilluminate the tissues and identify the blood vessel anatomy. The first branch vessel beyond the ligament of Treitz was preserved. The fourth branch of the superior mesenteric artery functioned as the distal vascular pedicle to the mobilized jejunal conduit. After test clamping demonstrated adequate collateral circulation, the proximal mesenteric vessels of the jejunal segment were ligated and divided close to their origin. The mesentery of the jejunum was then divided to the serosal border between the second and third mesenteric branches, allowing the conduit to completely unfurl. This straightens the sinusoid turns in the small bowel caused by a naturally foreshortened mesentery. Eliminating this step can lead to redundancy and poor flap function. The bowel was divided with a linear cutting stapler.

The conduit was then brought through the chest in either a retrosternal or posterior mediastinal position. In patients who required a retrosternal route, the thoracic inlet was enlarged. By using a sternal saw, the manubrium was divided in the midline from the sternal notch to the inferior level of the first rib. A perpendicular cut was next made just inferior to the left first rib and carried to join the previously made sternal incision. In this manner a portion of the manubrium, left clavicular head, and left first rib were resected to allow the jejunum to enter the neck without constriction. This approach also allowed access to the internal thoracic artery and vein for the purposes of mesenteric revascularization.

At this point, the conduit was trimmed to eliminate redundancy. The cervical anastomosis was performed with a single layer of interrupted 3-0 Vicryl sutures. A microvascular anastomosis was then performed between the proximal jejunal mesenteric arcade and either the internal thoracic vessels or branches of the external carotid artery and jugular vein. Occasionally, a saphenous vein graft was used to bridge a gap between the conduit and recipient vessels.

In the abdomen the distal portion of the conduit was anastomosed to the posterior wall of the stomach in a retrocolic retrogastric manner with a circular stapler. Jejunal continuity was reestablished through a stapled anastomosis. In the absence of a stomach, a Roux-en-Y anastomosis was performed. A nasogastric tube was passed through the conduit and secured in place. A feeding jejunostomy tube was routinely placed. 
TABLE 1. Demographics $(n=26)$

\begin{tabular}{lc}
\hline Age (y) & \\
Mean & 55.2 \\
Median & 55.1 \\
Range & $37-74.6$ \\
Sex & \\
Male & $18(69.2 \%)$ \\
Female & $8(30.8 \%)$ \\
Primary & \\
Esophageal cancer & $22(84.6 \%)$ \\
Other malignancy & $4(15.4 \%)$ \\
Tumor location & \\
Cervical & $4(15.4 \%)$ \\
Middle & $5(19.2 \%)$ \\
Lower & $5(19.2 \%)$ \\
Gastroesophageal junction & $10(38.6 \%)$ \\
Stomach & $1(3.8 \%)$ \\
Other & $1(3.8 \%)$ \\
Esophageal cancer stage (n $=22)$ & \\
I & $5(22.7 \%)$ \\
IIA & $6(27.3 \%)$ \\
IIB & $3(13.7 \%)$ \\
III & $7(31.8 \%)$ \\
IVA & 0 \\
IVB & $1(4.5 \%)$ \\
Preoperative chemotherapy & $13(50 \%)$ \\
Preoperative radiation therapy & \\
None & $13(50 \%)$ \\
$<45$ Gy & $6(23.1 \%)$ \\
$>45$ Gy & $7(26.9 \%)$ \\
Zubrod & \\
0 & $2(7.7 \%)$ \\
1 & $20(76.9 \%)$ \\
2 & $3(11.6 \%)$ \\
3 & 0 \\
4 & $1(3.8 \%)$ \\
\hline
\end{tabular}

A segment of redundant proximal jejunum was left attached to the revascularized mesenteric arcade and then externalized through the cervical wound to serve as a monitor flap. Once the interposed flap was proved viable (5-7 days postoperatively) the monitor flap was removed at the bedside by ligating and dividing its pedicle at skin level. A schematic of the procedure is provided in Figure 1.

Postoperatively, patients recovered in the surgical intensive care unit until they were deemed stable for transfer to the ward. Enteral feeding was initiated as soon as possible. Patients routinely had a contrast esophagram on day 7 or earlier if indicated. If no leak was detected, the nasogastric tube was removed. Most patients were then started on a liquid diet and advanced to a postgastrectomy diet as tolerated.

\section{Results}

During the 4-year period, 26 patients were selected for esophageal reconstruction with an SPJ flap. Patient demographics are listed in Table 1. Esophageal carcinoma was the predominant malignancy, and tumors were most com-
TABLE 2. Preoperative symptoms $(n=26)$

\begin{tabular}{lc}
\hline Anorexia & $3(11.5 \%)$ \\
Dysphagia & \\
None & $10(38.5 \%)$ \\
Solids & $8(30.8 \%)$ \\
Liquids & $1(3.8 \%)$ \\
Discontinuity & $7(26.9 \%)$ \\
Reflux & \\
None & $14(53.8 \%)$ \\
Mild & $6(23.1 \%)$ \\
Moderate & $2(7.7 \%)$ \\
Severe & $4(15.4 \%)$ \\
Weight loss $>10$ lbs & $11(42.3 \%)$
\end{tabular}

\section{TABLE 3. Comorbidities $(\mathbf{n}=\mathbf{2 6})$}

\begin{tabular}{lc}
\hline Smoker & \\
$\quad$ Never & $12(46.1 \%)$ \\
Former & $11(42.3 \%)$ \\
$\quad$ Current & $4(15.4 \%)$ \\
Hypertension & $7(26.9 \%)$ \\
CAD & $1(3.8 \%)$ \\
Barrett's esophagus & $7(26.9 \%)$ \\
Achalasia & $1(3.8 \%)$ \\
COPD & $2(7.7 \%)$ \\
Diabetes & $2(7.7 \%)$ \\
Prior malignancy & $10(38.5 \%)$ \\
Prior foregut operation & $14(53.8 \%)$ \\
Prior chemotherapy & $6(23.1 \%)$ \\
Prior radiation therapy & $7(26.9 \%)$ \\
\hline CAD, Coronary artery disease; COPD, chronic obstructive & pulmonary \\
disease. &
\end{tabular}

monly encountered at the esophagogastric junction. More than half of these patients had received neoadjuvant therapy of some kind. The majority of patients were symptomatic from their disease, as indicated in Table 2. Seven (26.9\%) patients had previous procedures that resulted in esophagogastric discontinuity.

Patient comorbidities are presented in Table 3. The complex nature of this patient population is underscored by the high percentage of patients who had undergone prior foregut surgery, chemotherapy, and/or radiation therapy. Despite these facts, the overall performance status of the group was very good.

Indications for the use of an SPJ flap were varied, as indicated in Table 4. As experience was gained with this technique, 3 patients were offered SPJ flap reconstruction as a primary method of repair.

The operative results and complications are summarized in Tables 5 and 6. Twenty-four of twenty-six patients were ultimately discharged with an intact SPJ flap, for an overall success rate of $92.3 \%$. One patient experienced intraoperative flap loss caused by mesenteric arterial dissection during 
TABLE 4. Indications for use of jejunal flap $(n=26)$

\begin{tabular}{ll}
\hline Previous gastric surgery & 5 \\
Previous gastric radiation & 2 \\
Prior use of pedicled omental flap (absence of right & 2 \\
gastroepiploic artery) & 4 \\
Tumor involvement of stomach & 3 \\
High proximal resection line (proximal hypopharynx) & 5 \\
Failed pull-up with gastric necrosis & 2 \\
Recurrent tumor after esophagectomy & 3 \\
\hline
\end{tabular}

TABLE 5. Results

\begin{tabular}{|c|c|}
\hline \multicolumn{2}{|l|}{ Esophagectomy type } \\
\hline Transhiatal & $10(38.5 \%)$ \\
\hline Three field & $11(42.3 \%)$ \\
\hline Prior resection & $5(19.2 \%)$ \\
\hline \multicolumn{2}{|l|}{ Conduit location } \\
\hline Posterior mediastinum & $13(50 \%)$ \\
\hline Retrosternal & $13(50 \%)$ \\
\hline Mortality & 0 \\
\hline Flap survival & $24 / 26(92.4 \%)$ \\
\hline \multicolumn{2}{|l|}{ Operative time $(\mathrm{h})$} \\
\hline Mean & 12.4 \\
\hline Median & 12.1 \\
\hline Range & $8-17$ \\
\hline \multicolumn{2}{|l|}{ Estimated blood loss (mL) } \\
\hline Mean & 1441 \\
\hline Median & 1000 \\
\hline Range & $250-6000$ \\
\hline Patients transfused & $16(61.5 \%)$ \\
\hline \multicolumn{2}{|l|}{ Length of stay (d) } \\
\hline Mean & 23.8 \\
\hline Median & 18 \\
\hline Range & $10-73$ \\
\hline \multicolumn{2}{|l|}{ Enteral intake at discharge } \\
\hline Solid & $15(57.8 \%)$ \\
\hline Full liquid & $3(11.5 \%)$ \\
\hline NPO & $8(30.7 \%)$ \\
\hline \multicolumn{2}{|c|}{ Supplemental diet at discharge } \\
\hline Enteral & $25(96.2 \%)$ \\
\hline None & $1(3.8 \%)$ \\
\hline \multicolumn{2}{|l|}{ Discharge to } \\
\hline Home & $21(80.8 \%)$ \\
\hline Rehab & $5(19.2 \%)$ \\
\hline
\end{tabular}

NPO, Nothing by mouth.

the transfer of the flap through the chest. This patient was subsequently reconstructed with a gastric pull-up. One other flap loss occurred during the early postoperative period in a patient with abdominal compartment syndrome and multisystem organ failure after a prolonged reconstruction. There were $6(23 \%)$ patients who were discharged without experiencing any postoperative events. Cervical anastomotic leaks occurred in 5 (19.2\%) patients, all of which resolved
TABLE 6. Complications

\begin{tabular}{lc}
\hline Flap loss & $2(7.7 \%)$ \\
Early reoperation & $2(7.7 \%)$ \\
Leaks & \\
$\quad$ Cervical anastomosis & $5(19.2 \%)$ \\
$\quad$ Midconduit perforation & $2(7.7 \%)$ \\
Arrhythmia & $8(30.7 \%)$ \\
Wound infection & $7(26.9 \%)$ \\
Pneumonia & $6(23.1 \%)$ \\
Pleural effusion & $6(23.1 \%)$ \\
Reintubation & $5(19.2 \%)$ \\
Recurrent nerve palsy & $3(11.5 \%)$ \\
Sepsis/MSOF & $2(7.7 \%)$ \\
ARDS & $2(7.7 \%)$ \\
Empyema & $2(7.7 \%)$ \\
MI & $1(3.8 \%)$ \\
DVT & $1(3.8 \%)$ \\
\hline MSOF, Multiple systems organ failure; ARDS, adult respiratory distress \\
syndrome; MI, myocardial infarction; DVT, deep venous thrombosis.
\end{tabular}

with neck drainage and local wound care. Four of these leaks occurred in patients with retrosternal conduits. Two patients had delayed presentation of midconduit perforations. One of these was well drained by existing chest tubes and resolved with conservative management. The other required thoracotomy and primary repair. In both of these patients, difficulty with passing the nasogastric tube through the conduit likely caused these injuries. One additional patient required early reoperation for an acute abdomen caused by cecal ischemia. There were no operative, 30-day, or in-hospital mortalities, and $80.8 \%(\mathrm{n}=21)$ of patients were discharged directly to home.

At the time of discharge, $69.3 \%(\mathrm{n}=18)$ of the patients were tolerating an oral diet. Only 8 patients were discharged with orders to take nothing by mouth. One was because of recurrent aspiration, and the remainder were because of leaks. Ninety-six percent $(n=25)$ of patients were discharged with supplemental tube feeding.

Of the 24 patients successfully treated with an SPJ flap, 22 survived at least 6 months after their reconstruction. We were able to obtain functional data in $95.4 \%(\mathrm{n}=21)$ of these cases, with an average potential follow-up of 32 months (Table 7). Twenty (95.2\%) patients were tolerating a regular diet. The number of meals per day ranged from 2 to 6 . Only $23.8 \%(n=5)$ of the patients required prolonged supplemental enteral nutrition. Thirteen patients reported normal swallowing function. Five patients experienced occasional mild dysphagia with certain solid foods, and 5 patients reported occasional mild dysphagia with liquids at extremes of temperature. Contrast studies in these patients demonstrated widely patent anastomoses without evidence of stricture. These symptoms appeared to result from differences in the rate of peristalsis between the residual esophagus and the interposed jejunum. These symptoms 
TABLE 7. Function after 6 months $(\mathbf{n}=21)$

\begin{tabular}{lc}
\hline Regular diet & $20(95.2 \%)$ \\
Tube feeds & $16(76.2 \%)$ \\
None & $4(19 \%)$ \\
Partial & $1(4.8 \%)$ \\
Full & \\
Dysphagia & $13(61.9 \%)$ \\
None & \\
Solids & $5(22.7 \%)$ \\
$\quad$ Mild & 0 \\
Severe & \\
Liquids & $5(22.7 \%)$ \\
$\quad$ Mild & 0 \\
Severe & $1(4.8 \%)$ \\
Stricture-dilation & \\
Reflux & $20(95.2 \%)$ \\
None & $1(4.8 \%)$ \\
Mild & 0 \\
Severe & \\
Dumping & $17(80.9 \%)$ \\
None & $3(14.3 \%)$ \\
Mild & $1(4.8 \%)$ \\
Severe & \\
\hline
\end{tabular}

were easily controlled with dietary modification. Reflux symptoms were absent in $95.2 \%(\mathrm{n}=20)$ of the patients, and $80.9 \%(\mathrm{n}=17)$ had no dumping symptoms.

Few patients have required remedial procedures. One patient required repair of an incisional hernia. Dilation of a midconduit stricture was required in 1 patient. One patient presented 18 months after retrosternal interposition with progressive reflux and regurgitation. Contrast studies and endoscopy demonstrated obstruction from a redundant conduit. He was successfully managed with a stapled jejunojejunostomy, bypassing the redundant segment. Out of the 15 patients working before this operation, $6(40 \%)$ have returned to their previous professions. To date, 12 patients are alive with no evidence of disease, 4 are alive with recurrent disease, 7 are dead of their disease, and 3 are dead of other causes.

\section{Discussion}

The stomach and colon have proved to be acceptable esophageal replacement conduits, although neither has emerged as the ideal esophageal substitute. The stomach has a reliable blood supply, is relatively easy to pull up, and requires just one anastomosis to complete the reconstruction. A gastric conduit has specific disadvantages, however. The normal stomach length, when fashioned as a conduit, might not be consistently suitable for long-segment reconstruction involving the proximal hypopharynx. Furthermore, gastric interposition procedures might be associated with symptomatic reflux and positional regurgitation. ${ }^{6}$ Patients with an intrathoracic esophagogastric anastomosis can experience metaplastic changes in the mucosa of the residual esophagus. ${ }^{7,8}$ These changes can progress to significant dysplasia or recurrent malignancy requiring additional treatment.

Pedicled colon can provide adequate length for total esophageal reconstruction and might alleviate some of the problems that arise in the long term after gastric interposition. Colon interposition, however, is not free from complication. The development of conduit redundancy over time impairs food transit, leading to an unpleasant sensation of fullness, troublesome regurgitation, and the need for remedial operations. ${ }^{2-5}$ The vascular anatomy is variable and can be adversely affected by atherosclerosis. Colonic necrosis, thought to result from arterial or venous insufficiency at the oral end of the pedicle, ${ }^{9}$ carries a significant mortality risk. ${ }^{10}$

In a distinct subset of patients, traditional gastric or colonic conduits are not available as esophageal replacements, either because of intrinsic disease, tumor involvement, or previous surgical intervention. Esophageal reconstruction in this group can prove daunting. In these patients we have evaluated the jejunum as an alternative conduit for total esophageal reconstruction.

The long-term durability of jejunum is well established. ${ }^{11}$ It is available in sufficient quantity and can be harvested with limited physiologic effect on gastrointestinal function. Jejunum is relatively free of intrinsic disease and provides a sterile conduit. It more closely approximates the diameter of native esophagus and also retains its peristaltic activity after transfer. Although the value and effectiveness of this peristalsis has been questioned, ${ }^{12}$ several studies have supported the functional importance of these contractions when compared with the passive colonic conduit. ${ }^{13-15}$

Esophageal reconstruction with a jejunal conduit is well described. Alexis Carrel reported his initial work on transplanting autologous small bowel into the necks of dogs in $1906 .{ }^{16}$ The first successful use of jejunum for esophageal reconstruction in a human patient was reported by Roux in $1907,{ }^{17}$ although the final stage of that reconstruction was not completed until 1911. By then, Yudin ${ }^{18}$ had used Roux's pedicled reconstruction technique with good results in an additional 11 patients and would use this technique in a total of 80 patients by 1944 . Despite his initial success, he advocated caution, noting that variability in small bowel vascular anatomy might preclude the use of this reconstruction in many patients. Caution was warranted, as demonstrated by Ochsner and Owens. ${ }^{19}$ Their review of the literature on Roux's technique up to 1934 noted that gangrene of the jejunal loop occurred in $22 \%$ of the reported cases. Inadequate conduit blood supply was thought to be the principal reason for the high failure rate. Influenced by this report, Longmire ${ }^{20}$ modified Roux's technique in 1946 while treating a patient with a cicatricial esophageal obstruction after lye ingestion. To reduce the chances of flap necrosis, he incorporated microvascular anastomoses be- 


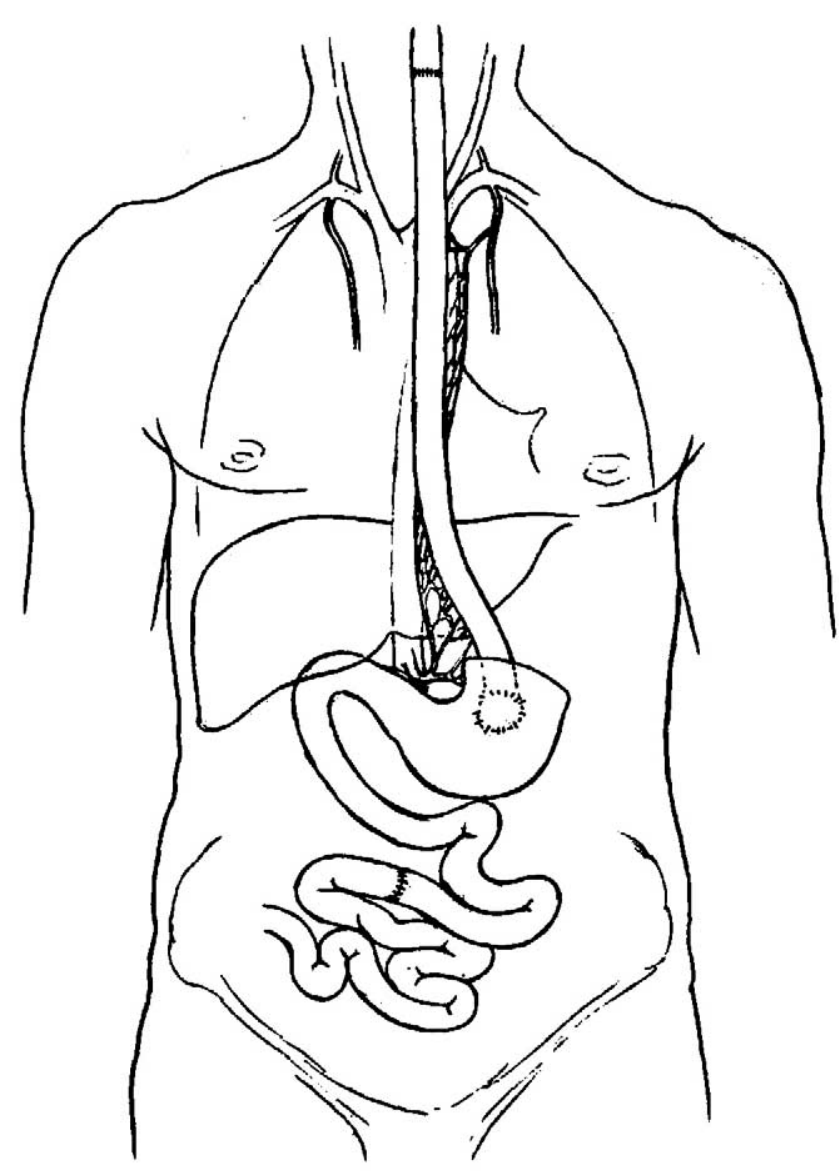

Figure 1. Completed augmented pedicled jejunal reconstruction.

tween the upper jejunal conduit mesenteric vessels and the internal thoracic vessels, thereby successfully augmenting its circulation. In 1956, Androsov ${ }^{21}$ reported using this vascular augmentation technique during esophageal reconstruction in 11 patients. Although these reports demonstrated that long-segment esophageal reconstruction with supercharged jejunum was possible, the technical complexities of the operation precluded its widespread acceptance. Subsequent use of jejunum was predominantly limited to short-segment repairs.

Refinement of microsurgical technique over the past 50 years has allowed surgeons to reconsider the supercharged technique advocated by Longmire. The published reports to date have shown encouraging results; however, most of these series were small, with varied indications and methods. ${ }^{22-27}$

Our series focuses on supercharged jejunum and its use in a complex group of 26 patients with cancer with limited reconstructive options. Many had prior malignancies and numerous prior operations. A significant number of these patients also received chemotherapy, radiation therapy, or both. Despite these challenges, we were able to perform successful reconstructions in $24(92.4 \%)$ of 26 of these patients by using the SPJ flap technique, with no mortality. Postoperative morbidity proved to be higher than in other series; however, most of the postoperative events were minor in nature. Of the 5 cervical anastomotic leaks, 2 were in salvage patients who had undergone previous definitive chemoradiation therapy to the head and neck, and 3 were in patients with esophagogastric discontinuity. Our leak rate compares with what has been reported in the literature for salvage and discontinuity patients. ${ }^{28-30}$ All of these anastomoses healed with conservative management, and none required dilation.

From a functional standpoint, the SPJ conduit proved very successful. Six months after the operation, more than $95 \%$ of patients had resumed a regular diet. Most patients reported normal swallowing. Those with occasional dysphagia classified it as mild and generally avoidable with dietary discretion. The majority were free from the reflux and dumping symptoms that can often follow esophagectomy.

Although functional benefits exist, caution is advocated when considering this technique for primary repair in the presence of a viable stomach. Experience has allowed us to expand the application of this technique within our practice; however, it remains a technically demanding operation best suited for patients with no other reconstructive options.

The supercharged pedicled jejunal flap provides highly selected patients with a suitable alternative conduit for total esophageal reconstruction when traditional replacement conduits are not available or appropriate. This procedure can provide excellent functional outcomes, despite the technical challenges in this complex patient population.

\section{References}

1. DeMeester TR, Johansson KE, Franze I, et al. Indications, surgical technique, and long-term functional results of colon interposition or bypass. Ann Surg. 1988;208:460-74.

2. Urschel JD. Late dysphagia after presternal colon interposition. Dysphagia. 1996;11:75-7.

3. Cense HA, Visser MR, van Sandick JW, et al. Quality of life after colon interposition by necessity for esophageal cancer replacement. J Surg Oncol. 2004;88:32-8.

4. Domreis JS, Jobe BA, Aye RW, Deveney KE, Sheppard BC, Deveney $\mathrm{CW}$. Management of long-term failure after colon interposition for benign disease. Am J Surg. 2002;183:544-6.

5. Jeyasingham K, Lerut T, Belsey RH. Revisional surgery after colon interposition for benign oesophageal disease. Dis Esophagus. 1999; 12:7-9.

6. Aly A, Jamieson GG. Reflux after oesophagectomy. Br J Surg. 2004; 91:137-41.

7. Lord RV, Wickramasinghe K, Johansson JJ, DeMeester SR, Brabender J, DeMeester TR. Cardiac mucosa in the remnant esophagus after esophagectomy is an acquired epithelium with Barrett's-like features. Surgery. 2004;136:633-40.

8. Oberg S, Johansson J, Wenner J, Walther B. Metaplastic columnar mucosa in the cervical esophagus after esophagectomy. Ann Surg. 2002;235:338-45.

9. Fujita H, Yamana H, Sueyoshi S, et al. Impact on outcome of additional microvascular anastomosis-supercharge-on colon interposition 
for esophageal replacement: comparative and multivariate analysis. World J Surg. 1997;21:998-1003.

10. Briel JW, Tamhankar AP, Hagen JA, et al. Prevalence and risk factors for ischemia, leak, and stricture of esophageal anastomosis: gastric pull-up versus colon interposition. J Am Coll Surg. 2004;198:536-41.

11. Ring WS, Varco RL, L'Heureux PR, Foker JE. Esophageal replacement with jejunum in children: an 18 to 33 year follow-up. $J$ Thorac Cardiovasc Surg. 1982;83:918-27.

12. Smith RW, Garvey CJ, Dawson PM, Davies DM. Jejunum versus colon for free oesophageal reconstruction: an experimental radiological assessment. Br J Plast Surg. 1987;40:181-7.

13. Meyers WC, Seigler HF, Hanks JB, et al. Postoperative function of "free" jejunal transplants for replacement of the cervical esophagus. Ann Surg. 1980;192:439-50.

14. Wright C, Cuschieri A. Jejunal interposition for benign esophageal disease. Technical considerations and long-term results. Ann Surg. 1987;205:54-60.

15. Moreno-Osset E, Tomas-Ridocci M, Paris F, et al. Motor activity of esophageal substitute (stomach, jejunal, and colon segments). Ann Thorac Surg. 1986;41:515-9.

16. Carrel A. The surgery of blood vessels. Bull Johns Hopkins Hosp. 1907;190:18-27.

17. Roux C. A new operation for intractable obstruction of the esophagus (L'oesophago-jejuno-gastrosiose, nouvelle operation pour retrecissement infranchissable del'oesophage). Semin Med. 1907;27:34-40.

18. Yudin SS. The surgical construction of 80 cases of artificial esophagus. Surg Gynecol Obstet. 1944;78:561-83.

19. Ochsner A, Owens N. Antethoracic oesophagoplasty for impermeable stricture of the oesophagus. Ann Surg. 1934;100:1055-91.

20. Longmire WP. A modification of the Roux technique for antethoracic esophageal reconstruction. Surgery. 1947;22:94-100.

21. Androsov PI. Blood supply of mobilized intestine used for an artificial esophagus. AMA Arch Surg. 1956;73:917-926.

22. Hirabayashi S, Miyata M, Shoji M, Shibusawa H. Reconstruction of the thoracic esophagus, with extended jejunum used as a substitute, with the aid of microvascular anastomosis. Surgery. 1993;113:515-9.

23. Huang JL, Duan ZQ, Li Y, et al. Esophageal reconstruction by jejunal transfer. Ann Plast Surg. 1999;42:658-61.

24. Chen HC, Tang YB. Microsurgical reconstruction of the esophagus. Semin Surg Oncol. 2000;19:235-45.

25. Heitmiller RF, Gruber PJ, Swier P, Singh N. Long-segment substernal jejunal esophageal replacement with internal mammary vascular augmentation. Dis Esophagus. 2000;13:240-2.

26. Chana JS, Chen HC, Sharma R, Gedebou TM, Feng GM. Microsurgical reconstruction of the esophagus using supercharged pedicled jejunum flaps: special indications and pitfalls. Plast Reconstr Surg. 2002;110:742-8.

27. Sekido M, Yamamoto Y, Minakawa H, et al. Use of the "supercharge" technique in esophageal and pharyngeal reconstruction to augment microvascular blood flow. Surgery. 2003;134:420-4.

28. Barkley C, Orringer MB, Iannettoni MD, Yee J. Challenges in reversing esophageal discontinuity operations. Ann Thorac Surg. 2003;76: 989-94.

29. Sakuraba M, Kimata Y, Hishinuma S, Nishimura M, Gotohda N, Ebihara S. Importance of additional microvascular anastomosis in esophageal reconstruction after salvage esophagectomy. Plast Reconstr Surg. 2004;113:1934-9.

30. Swisher SG, Wynn P, Putnam JB, et al. Salvage esophagectomy for recurrent tumors after definitive chemotherapy and radiotherapy. J Thorac Cardiovasc Surg. 2002;123:175-83.

\section{Discussion}

Dr Joseph I. Miller, Jr (Atlanta, Ga). I wish to congratulate the authors on a remarkable surgical forte in this group of highly complex and technically challenging patients.

The value of the presentation is to look at the complexity of the patients presented, with their previous surgical history, comorbidities, and previous chemoradiotherapy. They presented 26 patients, of whom 24 were discharged with an intact supercharged pedicled jejunal flap, for a $92.3 \%$ success rate, which is indeed a remarkable feat. One really has to read the article to appreciate the complexity of the cases. The use of stomach and colon when available is well documented in the article, and the indications for use of the supercharged flap are well outlined.

I have several questions for the author. Could you be a little more specific in what supercharging means? As I read the article, it seems that you have used standard microvascular techniques with the internal thoracic and cervical vessels.

Dr Ascioti. The term supercharged is taken from our plastic surgical colleagues. It is merely another term for a microvascular augmentation. The entire circulation to the proximal jejunal segment is based on that microvascular anastomosis, whereas the distal jejunum derives its blood supply from the pedicle within the abdomen.

Dr Miller. Thank you.

How exactly is the anastomosis constructed, still leaving a monitor flap? Do you worry about ligating that and then having some sort of retrograde infection back to your anastomosis? Would you comment on leaving the monitor flap or exactly how you can construct the anastomosis?

Dr Ascioti. The monitor flap is merely fashioned from the redundant bowel that is brought up into the neck. The mesentery of that flap is based on the same mesentery that is perfused by the microvascular anastomosis. Therefore we merely divide the mesentery to allow that flap to be mobile and reside outside the neck wound. The blood supply to both the interposed jejunum, as well as the monitor flap, is one and the same, and after about 5 days, we are able just to ligate that pedicle without affecting the blood supply to the residual interposition.

Dr Miller. In your article you stated that the cervical anastomosis was done with one layer of interrupted 3-0 Vicryl sutures. Your cervical leak rate is fairly high, greater than $19 \%$. Granted, they all did well with conservative management. Have you considered using Orringer's technique with the Endo-30 stapler? His leak rate went from $15 \%$ to $17 \%$ down to approximately $2 \%$.

Dr Ascioti. In selected patients end-to-end anastomosis was the only possible way of doing it. The size match is most appropriate in that manner. In certain patients a stapled anastomosis might be possible, and we are looking into that after having looked over our data in the past 4 years.

Dr Miller. In the article the mean operative time was approximately 12 hours, with the longest being 18 hours. Is this due to the reentry problems, is it trouble with a flap harvest, or is it due to the plastic surgeons with their microvascular technique?

Dr Ascioti. A lot of the time in these patients can be spent on reentry and flap mobilization. We are very careful to orient the flap correctly as it is brought through the chest to ensure that the pedicle is not kinked in any way and to make sure that the blood vessels line up appropriately. The microvascular anastomosis takes, on average, usually a little over an hour for just the arterial and venous anastomosis to be done.

Dr Miller. In conclusion, this is an outstanding article and a remarkable surgical achievement. The authors are to be congratulated.

Dr Ascioti. Thank you, Dr Miller.

Dr David H. Harpole, Jr (Durham, NC). This is an elegant study. I guess the only question I had I could not get from your 
presentation. You have the monitor flap there that you are looking at. Did you follow this? Were there reoperations for ischemia that you saw that were demonstrated by the small monitor flap? If you did not have any in 20 cases, I am kind of wondering why you need the monitor flap. Why couldn't you just put some flow probes down through the wound on the microvascular anastomosis, which you could pull out through the wound in a couple days, you know, to be able to follow the anastomosis itself or the bowel?

Dr Ascioti. Thank you for the question.

The monitor flap is a very accurate way to monitor both arterial and venous problems, and because we can often be fooled by the presence of arterial symptoms, that does not always prove to us that there is not a problem with the venous circulation. Therefore it allowed us a very simple and easy way to do that, which we were able to provide for the patients.

Dr Mark S. Allen (Rochester, Minn). How do you reassure the patients preoperatively when they wake up and see a segment of exposed jejunum in their neck?

Dr Ascioti. We tell them it is only going to be there for a few days. They do not seem to mind.

Dr Harpole. How many times did you re-explore on the basis of the flap?

Dr Ascioti. We did not. There were no patients who had any problems. There was one patient who we took back, the patient who lost the conduit within 3 days after the operation because of multisystem organ failure. She had persistent arterial inflow but had a problem with venous congestion, and that patient prompted us to take the flap out.

Dr John E. Foker (Minneapolis, Minn). I would like to compliment you on an excellent article.

Twenty years ago, we presented to this Association a series of long-segment jejunal interpositions followed for up to 33 years. There had been no graft failures, and all were eating normally. At least one is still eating well 50 years later. Also, as you probably know, jejunal interpositions are the only grafts to maintain peristalsis. At the same time, we described how to take down the arcades to gain a great deal of length, enough to easily reach the neck and to reduce redundancy.

Two years ago, I simplified the procedure by first dividing the left triangular hepatic ligament and used the ligament to move the left lobe of the liver out of the way. Then the jejunal limb was brought through the right hemidiaphragm, in front of the right hilum, up high in the chest. This proved to be an excellent approach, which simplified the procedure.

My question is this: Given the far superior performance of the jejunum and lack of serious consequences, such as reflux, dumping, malnutrition, atrophic gastritis, et cetera, et cetera, why not use it preferentially, particularly in those with a longer expected survival?

Dr Ascioti. Thank you for the question.

I think at Anderson our preferred conduit is still the stomach, but we are looking at the use of jejunum in selected patients because of concerns with intrathoracic gastric pull-up and the incidence of reflux and potential for future metaplasia and dysplasia within the residual esophagus, and we have been incorporating the use of jejunum as an interposition in vagal-sparing esophagectomies. We are evaluating that thoroughly, but I still think that it is a very large operation that should be required only in certain circumstances in which traditional conduits are not available.

Dr Foker. It does not have to be.

Dr Steven R. DeMeester (Los Angeles, Calif). That was a very elegant presentation.

I have 2 quick questions. Did you use any antiplatelet therapy or anticoagulation early or long-term postoperatively in these patients?

Dr Ascioti. The patients were only maintained on subcutaneous heparin postoperatively.

Dr DeMeester. Second, can you describe for us the distal connections? Was it all to Roux limbs, or did you connect to the stomach? How did you construct distally?

Dr Ascioti. It depended on the anatomy within the stomach. Obviously in patients without a gastric remnant, we did a Roux-en-Y, and in patients with a partial gastric remnant, we would connect up to that.

Dr DeMeester. How much of a gastric remnant would you recommend leaving? Did you have problems with reflux or regurgitation or with strictures from acid complications if you left too much stomach?

Dr Ascioti. No. We did not experience any complications at the distal anastomosis. We hooked into whatever was left.

Dr Pasquale Ferraro (Montreal, Quebec, Canada). Do you have any experience with the short jejunal segment? We have done 5 or 6 with the ear, nose, and throat surgeon, and instead of doing a gastric interposition, we just used a free flap with the jejunum to reconstruct the cervical esophagus. One comment, we also used the monitor flap, just as you showed it, and it works very nicely.

Dr Ascioti. Thank you for your question.

We have used a free jejunal segment interposition in patients who have a cervical recurrence after a colon interposition. We had a couple cases in which we have done that, and the ear, nose, and throat surgeons have some experience working with our plastic surgeons with jejunal free interpositions for short-segment resections.

Dr Raphael Bueno (Boston, Mass). I enjoyed your presentation.

Where would you place a colon interposition in your armamentarium? It seemed to me that in some of the cases that you demonstrated, all the problems were with the stomach not being available for interposition. It was not clear that the colon might not have been available.

Dr Ascioti. Thank you, Dr Bueno. That is a very good question.

In the initial operation in which we used this technique, the patient had a previous gastric wrap with Marlex mesh, and everything was very adherent to the stomach, including the transverse colon, splenic flexure, spleen, and omentum, and by the time the stomach was resected and the esophagus was resected, the colon was rather beat up and not, we thought, appropriate for a colon interposition. It was at that point we decided to use the jejunal technique. Subsequent to that, we had taken patients to the operating room prepared to use either jejunum or colon, and the decision was made intraoperatively on the basis of the size of the colon, the bulkiness of the potential conduit, and other factors that we went with jejunum. Once we started to realize the functional outcomes that we were achieving with the jejunum, we became more interested in looking at this as an alternative to the colon. 